\title{
Desenhando na escuridão
}

\author{
Drawing in the dark
}

Vilma Villarouco, Angela R. B. Flores

geometria para cegos, recursos didáticos

virtuais,

ensino de geometria geometry for the blind, virtual teaching resources, teaching geometry
Embora a educação de pessoas com deficiência venha recebendo atenção crescente nas últimas décadas, muito pouco se tem encontrado, quando o mote da inclusão refere-se ao desenvolvimento de Ambientes Virtuais de Aprendizagem Inclusivos (AVA-I). Nesse cenário, trata-se neste artigo da educação de pessoas com deficiência visual séria ou cegueira total, e a inclusão digital destes, a partir do ensino via AVA's inclusivos. Essa tarefa importante e complexa é ampliada quando o tema a ser abordado trata da geometria. $\mathrm{O}$ artigo aborda um projeto em desenvolvimento que visa levar a geometria plana e tridimensional a estudantes com deficiência visual através de um AVA (Ambiente Virtual de Aprendizagem), trazendo conceitos, técnicas e conteúdos por meio de recursos hipermidiáticos, adaptando-os aos conceitos da acessibilidade e do Desenho Universal. Os resultados obtidos na pesquisa são aqui tratados com detalhes, incluindo as estruturas que originam as telas do Ambiente Virtual, bem como a fundamentação que apoia as proposições.

Although the literature shows that increasing attention in the last 30 or so years has been given to educating people with special needs, there is very little on the theme of inclusion regarding the development of Inclusive Virtual Learning Environments (I-VLE). It is against this background that this article addresses educating people whose sight is seriously impaired or who are totally blind, and their digital inclusion based on teaching them via inclusive VLEs. This important and complex task is magnified when the theme to be tackled concerns geometry. The article discusses an on-going project that seeks to offer planar and three-dimensional geometry to visually-impaired students within a VLE (Virtual Learning Environment), and to do so by introducing concepts, techniques and content by using hypermedia resources, and adapting them to the concepts of accessibility and Universal Design. The research results are discussed in detail, including the structures underpinning Virtual Environment screens, as are the theoretical foundations that support the propositions.

\section{Introdução}

Concebido como sendo de responsabilidade da Educação Especial, que é dotada de 'pessoal especializado' para trabalhar com as dificuldades, o ensino de pessoas com deficiência é frequentemente encarado como 
uma barreira, como um desafio ao professor das classes regulares. Estes, acreditando que não têm as habilidades para educar com êxito alunos com deficiência, resolvem deixar o caso para alguém mais especializado, mesmo antes de qualquer aprofundamento no conhecimento das necessidades desses alunos.

No ano de 1991 no Brasil, uma importante ação foi realizada, no sentido de criar estratégias de uniformização na forma de tratar a educação especial. A partir do entendimento da necessidade de integrar as ações conduzidas isoladamente, seja por esferas federais, estaduais ou municipais, foi realizado um encontro sob coordenação da CORDE (Coordenadoria Nacional para Integração da Pessoa Portadora de Deficiência) e do Ministério da Educação. Neste encontro a situação foi analisada sob uma retrospectiva histórica e conceitual, sendo traçados objetivos e princípios para o lançamento, em janeiro de 1992, do documento 'Subsídios para a elaboração da política nacional para integração das pessoas portadoras de deficiência no sistema regular de ensino'.

O objetivo principal era incorporar física e socialmente as pessoas com deficiência no ensino regular, garantindo-lhes oportunidades de acesso, ingresso e permanência no sistema educacional. Foi sem dúvida uma iniciativa necessária no sentido da inclusão.

Mazzota (1996) defende que a Educação Especial, inserida no processo de inclusão, se caracteriza como modalidade de ensino que apresenta um conjunto de recursos e serviços educacionais especiais, organizados para dar apoio, suplementar e, em alguns casos, substituir os serviços educacionais comuns, de modo a garantir a educação formal dos educandos que apresentem necessidades educacionais muito diferentes das da maioria das crianças e jovens. Em um sentido mais amplo, o ensino inclusivo é a prática da inclusão de todos independentemente de seu talento, deficiência - em escolas e salas de aulas provedoras, onde todas as necessidades dos alunos são satisfeitas (sTAINBACK, 1999).

A evolução dessas teorias trouxe à luz do entendimento o conceito de escola inclusiva, que Stainback (1999) define como sendo o lugar do qual todos fazem parte, em que todos são aceitos, onde todos ajudam e são ajudados por seus colegas e por membros da comunidade escolar, para que suas necessidades educacionais sejam satisfeitas.

Contribui nessa direção a atual LDB (LEI 9394/96), baseada no princípio do direito universal à educação para todos, trouxe diversas mudanças em relação às leis anteriores. No artigo 58 encontra-se: Entende-se por educação especial, para os efeitos desta Lei, a modalidade de educação escolar, oferecida preferencialmente na rede regular de ensino, para educandos portadores de necessidades especiais.

É nesse contexto que está inserido o presente artigo, no espaço que trata da inclusão de pessoas com deficiências, aqui utilizando tecnologias da informação como facilitadores dessa inclusão. 
Sob tais premissas, a pesquisa apresentada no presente trabalho trata de promover a inclusão também no EAD (Ensino A Distância), desenvolvendo um Ambiente Virtual de Aprendizagem Inclusivo (AVA-I) para conteúdos de geometria, com base nos princípios do Desenho Universal onde todos devem ser contemplados com acesso igualitário.

Nessa direção, o trabalho aqui relatado visa contribuir com material acessível, a uma área ainda muito pouco explorada.

\section{0 projeto em desenvolvimento}

A pesquisa vem percorrendo caminhos importantes desde sua concepção e iniciação, contando já com trabalhos desenvolvidos por membros da equipe em dissertações e teses, que envolvem o estudo de teorias da aprendizagem, de técnicas e ferramentas de interação pessoal e material das comunidades virtuais e do entendimento de como os cegos aprendem, passando pelo estudo dos Objetos de Aprendizagem (AO) Acessíveis e das diretrizes que norteiam a elaboração desses OA's.

A ideia inicial baseou-se na exploração de conteúdos da geometria tridimensional no AVA-I, a fim de permitir que pessoas com surdez e cegueira pudessem estudar elementos da representação espacial.

Na realidade, pretende-se colaborar para que pessoas com cegueira possam melhor entender o espaço que as circundam.

A percepção do espaço pelo cego se dá pela união de sensações táteis, sinestésicas e auditivas aliadas às experiências mentais passadas já construídas pelo sujeito. Assim, a falta da visão, por si só, não é um impedimento ao desenvolvimento; ela impõe caminhos diferenciados, uma vez que a obtenção de conhecimentos depende de uma organização sensorial diferente da do vidente (NUNES E LOMÔNACO, 2008). Seguindo este raciocínio Faé (2009) explica que a compreensão do espaço se dá através do entrelaçamento complexo da construção e da vivência dos aspectos da realidade. Sendo assim, a noção espacial não deriva somente da percepção, "há também a inteligência do sujeito que atribui significado aos objetos percebidos" (CASTELLAR, 2006, P.39).

Para compreender o que garante a inserção do deficiente visual, no cotidiano das relações sociais, adquirir mobilidade e desenvolver habilidades, inclusive de relacionamento, o deficiente visual precisa entender o mecanismo da representação, ou seja, da ação de representar dada informação obtida através de uma abstração, que indica imagem ou ideia - ou ambos - em semelhança com determinado objeto (ABBAGNANO, 2007).

De acordo com Bourdieu (1990), o deslocamento nos diferentes espaços proporciona ao deficiente visual estímulos da memória e da organização espaço-temporal que propiciam maior interação com a sociedade, permitindo movimentos do corpo e evitando seu isolamento. 
Portanto, a necessidade de ater-se a referências espaciais é um processo permanente para o deficiente visual, que vai se deparar ao longo de sua vida com a necessidade de movimentar-se ou de aprimorar qualquer resquício de resíduo visual.

Sendo através de geometria que se dá a representação de formas dos espaços edificados e urbanos, fomentou-se a necessidade do entendimento dessa importante relação.

Nesse contexto, interessava saber como pessoas cegas encaram os estudos de geometria e foi a realização de uma pesquisa com um pequena amostra de pessoas cegas que apontou para a necessidade da inserção de conteúdos de geometria plana, o que é tratado mais adiante neste artigo.

No desenvolvimento e disponibilização do AVA tem-se trabalhado na direção de adotar o MOODLE como ambiente base, pela possibilidade de inserção de materiais novos sempre que necessário e pela interação e mediação disponibilizada.

Sendo fundamentalmente inclusivo, o AVA pressupõe a adoção de leitor de tela para uso de pessoas cegas, bem como da exibição da interpretação em Libras, linguagem dos sinais, para pessoas com surdez, sendo necessário a adaptação do Moodle para inserção das imagens, leitores de tela, filmagem das interpretações em Libras, bem como os roteiros necessários ao bom desenvolvimento do AVA Inclusivo.

O recurso da audiodescrição também é adotado, visando permitir às pessoas cegas um melhor entendimento dos desenhos e das figuras inseridas nas telas.

Aqui cabe esclarecer que neste artigo nos ocuparemos apenas da área destinada as pessoas cegas, do AVA em desenvolvimento.

\subsection{Pesquisa inicial com pessoas deficientes}

O desenvolvimento da pesquisa teve apoio nas seguintes etapas e processos:

1. Revisão da literatura que trata das questões pertinentes à aprendizagem de como os cegos aprendem, de técnicas e ferramentas de interação pessoal, das comunidades virtuais, e de Objetos de Aprendizagem Acessíveis (OAAs);

2. Entrevistas não estruturadas focalizadas, como instrumentos da pesquisa qualitativa que buscou identificar os aspectos da necessidade do conhecimento, do interesse no aprendizado, dos conhecimentos sobre a da geometria plana e do interesse de participar dos estudos quando da testagem do AVA-I em desenvolvimento;

3. Mapeamento dos resultados e identificação dos itens e características das pessoas deficientes visuais. 
A população ou universo da pesquisa foi formado por pessoas com deficiência visual (cego e baixa visão) que aceitaram participar da pesquisa. A amostra foi do tipo intencional e determinada a partir dos critérios de inclusão e exclusão. Como critério de inclusão evidencia-se: ser deficiente visual, ter escolaridade em nível de médio ou acima, ter mais de 16 anos e aceitar participar da pesquisa. De forma análoga colocou-se como critério de exclusão: não ter idade e escolaridade mínima para participar desta pesquisa ou ainda não aceitar participar da mesma. Foram enviados via web questionários para diferentes cursos de EAD que possuem alunos com deficiência visual.

Para aplicação do questionário foram visitadas associações de pessoas cegas, além de tê-lo enviado a 87 pessoas que trabalham com tais deficientes. Estas pessoas repassaram o questionário aos seus alunos e do total enviado somente 14 questionários retornaram.

Ao final da aplicação do questionário junto à amostra, os dados foram tabulados e tratados conforme é descrito a seguir: Participaram da amostra pessoas de diferentes regiões do país, incluindo Minas Gerais, Maranhão, Rio Grande do Sul, Rio grande do Norte, Santa Catarina, Paraíba, Pernambuco, São Paulo, Maranhão, Paraná e Bahia, com idade média de 36,5 anos, todos possuem computador sendo que $64,28 \%$ utilizam com facilidade o computador, conforme demonstra a tabela 1.

Tabela 1 Idade e informatização

\begin{tabular}{lll}
\hline Idade (Média) & 36,5 anos \\
\hline Possui computador & $100 \%$ \\
\hline Uso do computador & Com facilidade & $64,28 \%$ \\
\cline { 2 - 3 } & \multicolumn{1}{l}{ Com Dificuldade } & $35,78 \%$ \\
\hline Possui Internet & $100 \%$ & \\
\hline Possui e-mail & $92,85 \%$ & \\
\hline Freqüência que abre os & Diária & $76,92 \%$ \\
\cline { 2 - 3 } e-mails & $3 \times \mathrm{p} /$ semana & $7,70 \%$ \\
\cline { 2 - 3 } & $4 \times \mathrm{p} /$ semana & $15,38 \%$ \\
\hline
\end{tabular}

\subsection{Configurando o perfil dos participantes}

Como se está trabalhando com um ambiente virtual de aprendizagem web, foi importante identificar as experiências dos usuários com o uso de computadores, leitores de tela, bem como o acompanhamento de cursos à distância. Também se buscou entender a relação dos pesquisadores com a geometria e seu interesse em aprofundar conhecimentos na matéria. 
Quanto ao uso de leitores de tela a maioria de 8 pessoas opta pelo NVDA e JAWS, seguido do DOSVOX, como demonstrado no gráfico no Gráfico 1.

Gráfico 1 Leitores de tela utilizados

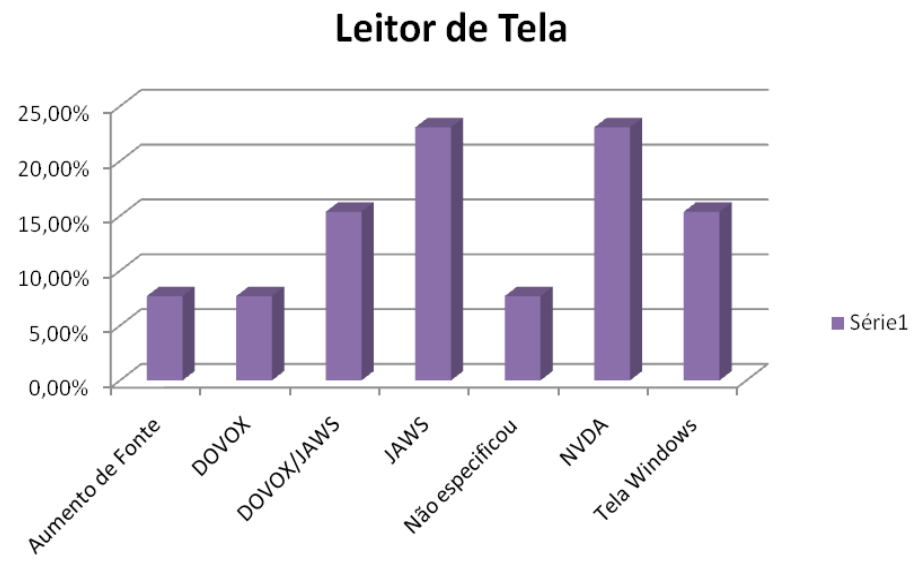

No grupo de perguntas referente à escolaridade, apenas $28,57 \%$ tem o nível médio, sendo a maioria de nível superior ainda que incompleto (gráfico 2)

Gráfico 2 Distribuição do nível de escolaridade dos respondentes

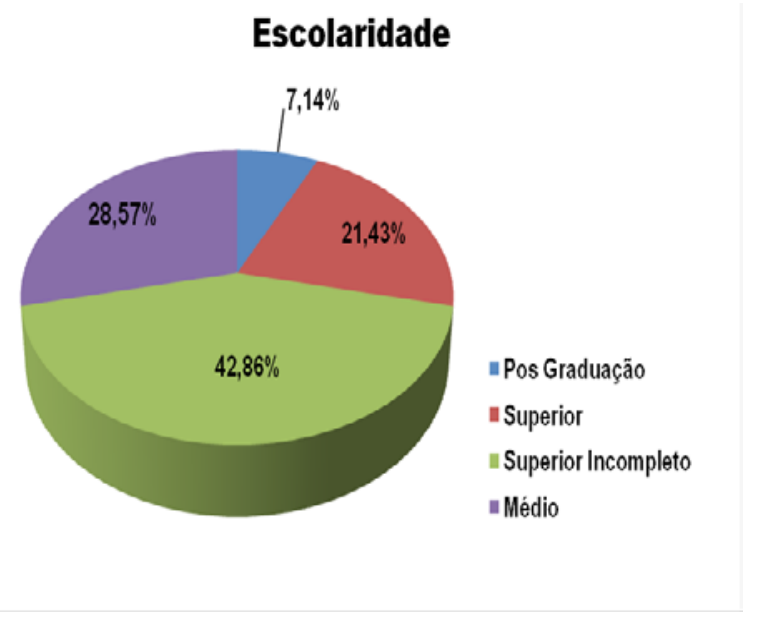

Com referência ao grupo de perguntas referente ao estudo da geometria, quase a totalidade já teve algum contato com a matéria e acha importante seu estudo. Quando solicitados a descrever figuras geométricas básicas como triângulos e retângulos, 60\% dos respondentes o fizeram de maneira incorreta. Alguns deixaram essas 
perguntas sem respostas e outros afirmaram saber descrever, mas não o fizeram.

Esses resultados foram determinantes para a inserção de conteúdos básicos nos estudos de geometria através do AVA-I.

Na pergunta que buscava entender qual a importância para as pessoas cegas estudarem geometria, muitas respostas referem-se à possibilidade de melhor entender e se situar no espaço. Alguns respondentes associam essa importância, inclusive a possibilidade de desenhar esboços de percursos, de distribuição de mobília em um ambiente desenhado, além de outras utilidades.

Quando perguntado do interesse em participar dos estudos quando da testagem do AVA-I em desenvolvimento pode-se verificar uma diferença significativa entre a quantidade de pessoas que atribuem importância ao estudo da geometria, e, aqueles que se dispõe a participar dos estudos quando da testagem. (Gráfico 3). Isso fica evidente quando são avaliados os comprimentos das barras azuis, bastante significativas nas duas primeiras perguntas, reduzindo-se quando se busca identificar sobre o interesse em estudar o assunto foco do Ambiente Virtual.

Gráfico 3 Estudos sobre Geometria

\section{Estudo e Interesse da Geometria}

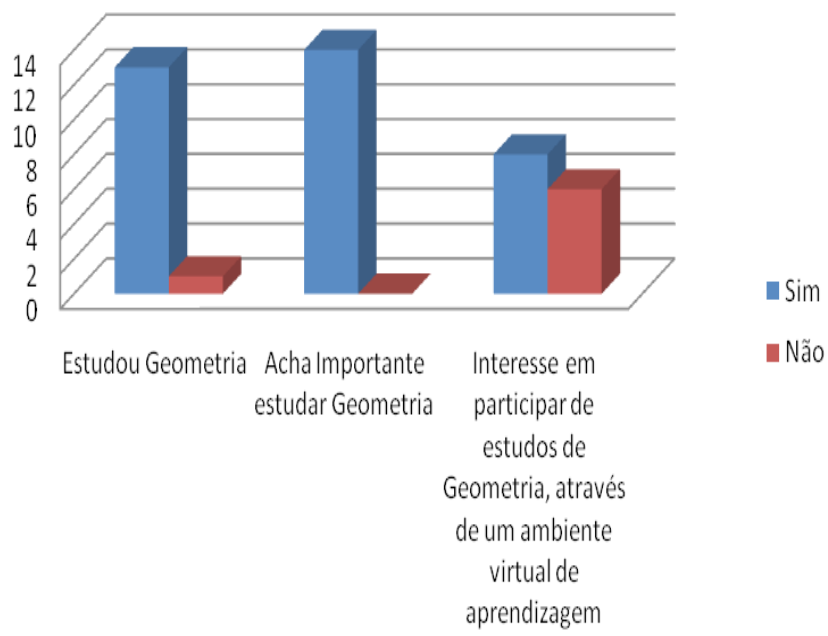

Também perguntou-se sobre experiências anteriores com a EAD. Muitos afirmaram já ter realizado estudos em cursos à distância, sendo relatado haver dificuldades por significativa parcela dos pesquisados.

Alguns relataram a ausência de preocupações com a acessibilidade em cursos EAD, onde um deles referiu estar em risco de não concluir seu curso superior à distância por esse motivo. 
Gráfico 4 Dificuldade de acompanhamento de curso EAD dos respondentes

\section{Acompanhamento de Curso EAD}

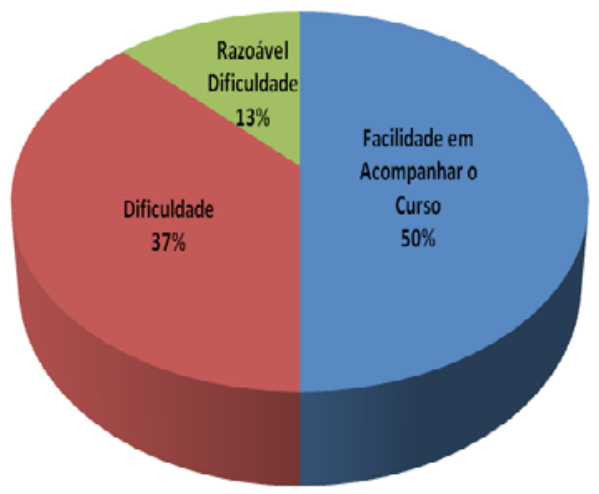

A consecução dessa parte da pesquisa tem sido de grande relevância, tendo levado a equipe de pesquisa a repensar a abrangência dos conteúdos a serem explorados no ambiente virtual em desenvolvimento.

Com tais resultados a equipe da pesquisa decidiu ampliar a aplicação dos questionários, estando em fase de coleta em Recife, em Florianópolis e ainda por internet com usuários de todo o país. No entanto, mesmo que nesta ampliação da amostra, sejam encontrados resultados diferentes em relação ao conhecimento da geometria básica, identifica-se como necessária a abordagem de tais conteúdos, permitindo o acesso aos que identifiquem necessidade de melhor conhece-los.

\subsection{Resultados da pesquisa}

Contando já com um significativo arcabouço teórico e metodológico e chegando à fase de desenvolvimento do AVA, utilizou-se o resultado da pesquisa a fim de identificar as maiores demandas e aspirações advindas dos usuários.

Também foi realizada entrevista semi-estruturada com três pessoas com cegueira, objetivando entender primeiramente o que os leva a ter interesse pelo estudo da geometria, bem como sondar seus conhecimentos sobre a matéria advindos da escola ou outros estudos já realizados. 
Em entrevista com 'Maria', cega desde o nascimento e voluntária a colaborar com a pesquisa, registra-se que para ela o estudo da geometria ajudaria a entender melhor o espaço que a circunda, possibilitando-lhe rascunhar o roteiro de um percurso para ensinar a alguém um endereço, ou ainda desenhar como gostaria que estivessem distribuídos os móveis do seu quarto.

Embora registre que já estudou geometria e afirme conhecer formas fundamentais como quadrado, retângulo e triângulo, não os consegue descrever nem desenhar assertivamente. Maria desenhou figuras curvas ao se referir aos triângulos, como se vê na figura 1.

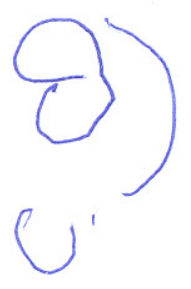

Figura 1 Desenho de Maria - Triângulos

A entrevistada exprime grande preocupação em como colocar dimensão no seu desenho quando visa representar um apartamento (de grandes dimensões) numa folha de papel (de pequenas dimensões). São as questões de escala que certamente devem ser cuidadosamente tratadas nos estudos da geometria no AVA.

Ao tentar esboçar o apartamento onde mora, Maria produziu o desenho a seguir.

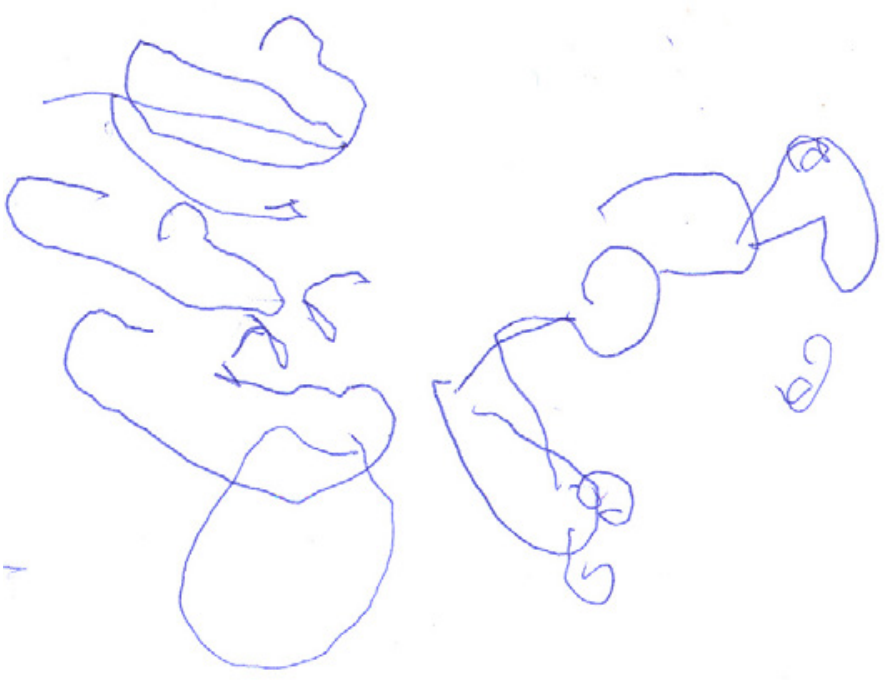

Figura 2 Desenho de Maria - Seu apartamento 
Outra entrevista realizada com o 'João' aponta para as mesmas dificuldades com as figuras geométricas planas e confirma a motivação para o estudo da matéria.

Nessa direção, Ventorini (2007) ao pesquisar sobre o sistema sensorial de apreensão do mundo em crianças cegas e com baixa visão em uma escola, observou que as formas de organização do espaço nos sujeitos deficientes visuais trazem as marcas de suas experiências. Por isso, organizam o espaço expressando rotas ou ambientes que possuam significativa vivência. Suas representações trazem informações atributivas que se referem às suas relações particulares e informações comuns como as localizações e características físicas dos objetos.

Pesquisadores no assunto afirmam que crianças e adolescentes representam ambientes maiores e com menos vivência por organização de rotas, e por organização configuracional os ambientes pequenos e conhecidos. Nesse sentido, a elaboração de maquetes tornou-se uma atraente atividade para aprendizagem, pois permitem ao aluno observar harmonia na distribuição espacial e na relação de proporção com os objetos, com o respeito às localizações distâncias e formas.

Nesse contexto, fica explícito tanto o interesse das pessoas com cegueira na temática, quanto a possibilidade de sucesso no estudo via ambiente virtual.

Foram as respostas à abordagem inicial que levaram a equipe à decisão de ampliar o quantitativo de respondentes, optando-se pela elaboração de um questionário que vem sendo aplicado tanto pessoalmente através de associações de cegos, quanto por envio via internet buscando conhecer como cegos estudam à distância, como se relacionam com o computador, leitores de tela, dificuldades encontradas nessa interação e de como eles percebem a geometria nos seus contextos diários.

Além disso, o desejo de melhor entender o espaço à sua volta e ampliar a possibilidade de lidar com representação de ambientes e mobiliários, evidencia a possibilidade e necessidade de criar meios de inserção de pessoas cegas nos processos participativos de projetos.

Nessa direção é salutar lembrar conceitos da ergonomia aplicada ao ambiente construído, quando aponta a obrigatoriedade de promover a satisfação do usuário a partir da sua participação nas decisões sobre os ambientes que irá ocupar.

Também em função do nível de conhecimentos sobre geometria que se tem identificado, ficou decidido que serão tratados inicialmente conteúdos bastante básicos, para garantir a uniformidade dos saberes dos estudantes. Tratar-se-á portanto, da geometria plana, partindo da identificação de linhas retas, curvas, paralelas, perpendiculares, bem como das figuras geométricas mais comuns.

O ambiente hipermidiático interativo está em fase de elaboração de storyboards com os objetos de aprendizagem. 
Paralelamente, os questionários continuam a ser preenchidos pela população alvo, uma vez que se busca ali identificar também parceiros interessados na utilização e testagem do AVA.

Até o momento já foram desenvolvidos conteúdos da geometria plana aqui abordados, bem como foram trabalhados conteúdos da geometria tridimensional. Diversas narrativas vem sendo utilizadas, como as histórias em quadrinhos, os contos, a audiodescrição, conjugados a fim de permitir a melhor estratégia para o entendimento, a depender do tipo de deficiência que o usuário apresente.

O grupo da informática que integra a equipe do projeto vem implementando todo material no ambiente inclusivo já disponível. A testagem se dá à medida que um bloco de conhecimentos esteja implementado no ambiente.

\section{Objetos de aprendizagem e storyboards}

No ambiente em desenvolvimento é fundamental que se trabalhe com Objetos de Aprendizagem (OA) acessíveis, ou seja, aqueles que são apresentados em mais de uma mídia simultaneamente.

$\mathrm{Na}$ figura 3 é apresentado o projeto de uma tela para o início dos estudos sobre retas e curvas, ressaltando-se a importância de explicar a necessidade de explorar as figuras pelo tato. Todas as telas devem permitir a impressão das figuras em impressora de relevo, ou, em impressão simples desde que uma pessoa vidente a torne perceptível pelo toque, como explicado na tela.

(Continua)

\section{Tenha intimidade com retas e curvas}
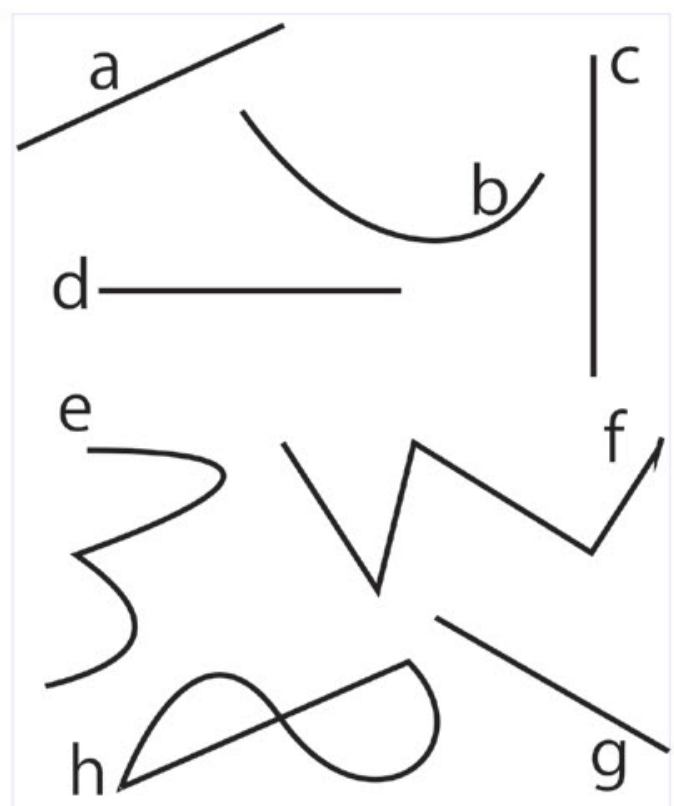

Figura 1
Neste módulo, vamos aprender sobre retas e curvas. Temos por definição que uma reta é a menor distância entre dois pontos.

Então, se você vai fazer uma caminhada de um local a outro, anda menos se for em linha reta. Mas se o seu objetivo é andar mesmo, vá da maneira mais interessante para seu caso.

Entretanto, no desenho, você não pode colocar curvas no lugar de retas, nem retas no lugar de curvas. Assim fazendo, você pode mudar completamente a figura desejada.

Clique aqui para ver uns exemplos interessantes antes de continuar. (Obs: fazer link para outra página)

Para seguir adiante, certificando-se que distingue bem uma reta de uma curva, você deve imprimir a figura ao lado e com auxílio de uma pessoa vidente, passar sobre as retas e curvas uma cola de relevo, ou caneta de relevo, ou colar um barbante sobre elas.

Identifique com o tato cada uma delas.

Observe que aqui nesse ambiente de estudo o mais importante é você reconhecer as figuras ao toca-

las ou vê-las.

Assim, saberá desenha-las quando for necessário. 
Figura 1: Várias imagens de linhas retas e curvas onde você vai poder identificar cada uma, e qual diferença você encontra entre as curvas e entre as retas apresentadas.

Texto alternativo: Figuras com oito imagens de retas e de curvas

Descrição: ilustraçao que mostra oito possibilidades de linhas retas e curvas, linha mista com reta e curva, retas com pontos de inflexão, reta em posição horizontal, vertical e inclinada.

\section{Descreva cada figura:}

A figura A é uma

E a Figura $B$ ?

A C é

E D é o que?

Ainda tem a F. O que é isso?

E a G?

E finalmente, o que temos na $\mathrm{H}$ ?

\section{Navegação}

Ah! Você já domina bem isso e não quer se deter aqui. Basta responder certinho e ir para a próxima etapa. Se errar aparece uma janela com a frase "analise melhor a situação e responda novamente"

Sai do objeto de aprendizagem

Figura 3 Storyboard: Tela retas e curvas

Essa afirmação pode ser traduzida na explicitação de que a abordagem sobre uma figura geométrica se dá em desenho, em texto escrito e verbalizado por um leitor de tela, ao tempo que é descrito em LIBRAS, podendo ainda ser audiodescrito, ou apresentado na forma de histórias em quadrinhos. É a necessidade do usuário que define o recurso mais adequado ao entendimento da matéria.

Aqui são colocadas estruturações de conteúdos para algumas das telas iniciais, abordando os conteúdos da geometria plana no Ambiente Virtual.

As figuras que compõem esta parte do AVA, dedicada à introdução da geometria plana para as pessoas cegas, permitem a navegabilidade acessível, quando o leitor de tela estará habilitado a informar sobre as funções de todos os botões e setas de navegação. Nele, o usuários define seu tipo de deficiência logo no início da navegação, ativando os recursos específicos para suas necessidades.

A abordagem de figuras geométricas é iniciada com conteúdos bastante básicos, como a diferenciação entre curvas e retas.

A tela mostrada na figura 4 apresenta ao usuário o estudo das posições de retas e entre elas. Também tráz exemplos práticos da vida cotidiana, permitindo fácil identificação do conteúdo explorado. 


\section{Ainda cuidando de retas: Posições}

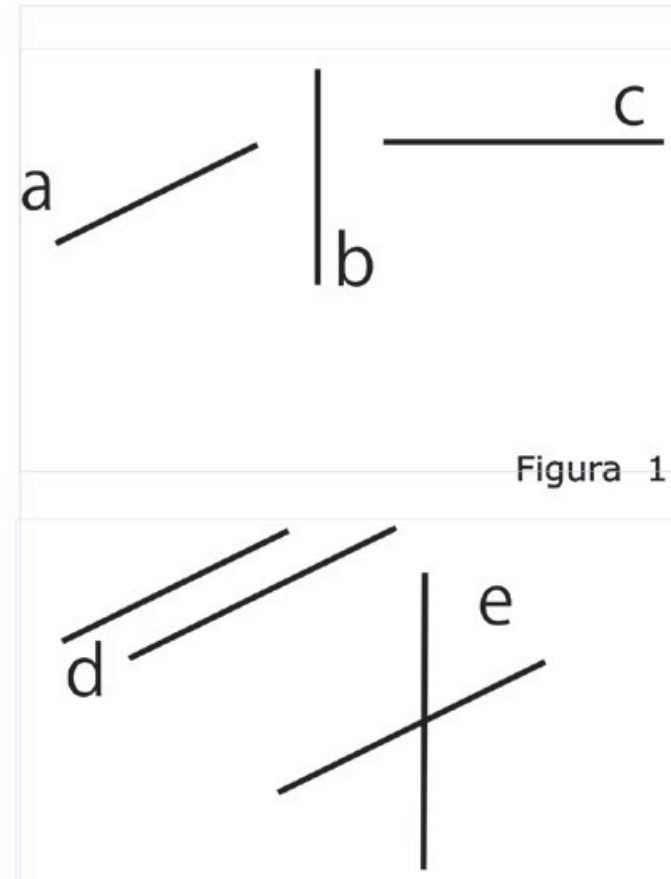

Figura 2

Agora vamos pensar um pouco sobre as retas. Como já dissemos, a reta é a menor distância entre dois pontos. Retas são entidades infinitas, mas quando no referimos a uma reta limitada, que vai da A a B, por exemplo, estamos tratando de um segmento, de uma porção de uma reta.

Bons exemplos de retas são as junções entre dois lados de uma caixa. Um lado tem uma reta comum com o outro que com ele se encontra. Pode ser também o encontro de duas paredes. forma uma reta.

$\mathrm{O}$ encontro entre uma parede e o piso também vai formar outra reta não é?

Vejamos então que o encontro das duas paredes vai gerar uma reta vertical, que fica em pé. Já o encontro da

parede com o piso forma uma reta deitada, horizontal.

Mas podemos ter também retas que não são horizontais nem verticais. Elas são inclinadas.

Estas posições de retas, bem como posição de uma em relação à outra, está desenhado no quadro ao lado.

Imprima em relevo e procure entende-las, relacionandoas com os exemplos aqui descritos.

Para entender melhor as posições de retas, e de situações de paralelismo, perpendicularismo e concorrência volte para a caixa de sapatos.

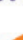

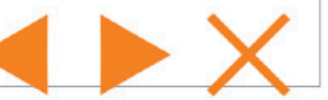

Figura 1: Reta inclinada (a); Reta vertical (b); Reta horizontal (c)

Figura 2: Retas paralelas (d); Retas concorrentes (e)
Figura 1:

Texto alternativo: Posições de retas.

Descrição: A figura mostra as 3 posições que uma reta pode assumir no espaço.

Sugere-se imprimir em relevo, ou mesmo em impressão plana normal, quando é possível torna-la em relevo, a partir da colagem de um barbante, ou cobrir o traço com cola de relevo.

\section{Exemplo 2:}

Texto alternativo: Posição de uma reta em relação a outra. Descrição: As figuras D e E mostram as posições entre duas retas em duas situações distintas. A primeira mostra duas retas paralelas. São retas que tem a distancia constante entre elas em toda extensão. A Segunda mostra duas retas concorrentes entre si, que são as que se cruzam e tem um ponto em comum.

\section{Navegação}

Ao clicar em caixa de sapatos vai para a página que mostra as caixas.

\section{Sai do objeto de aprendizagem}

Figura 4 Storyboard: Tela retas e suas posições 


\section{Curvas abertas e fechadas}

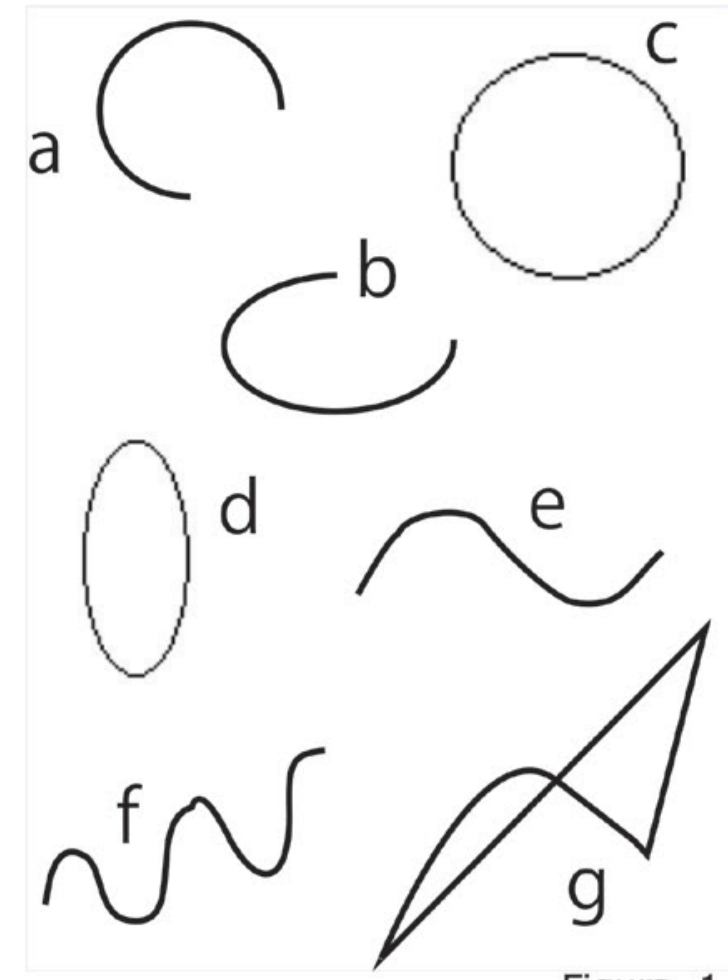

Aqui temos alguns exemplos de curvas.

As curvas podem ser fechadas ou abertas.

São linhas que não sendo retas, não apresentam pontos de inflexão angulares. Temos ao lado as figuras de $A$ até G. Toque com atenção cada uma delas. Achou algo diferente na G?

É que ela tem ponto de inflexão, ou seja, vértice. Não é contínua. Percebeu?

Logo, a figura $\mathrm{F}$ até contém uma parte curva, mas ela não é completamente uma curva, diferente das demais.

Ela apresenta três pontos de inflexão.

você consegue identifica-los?

Você vai ver que as figuras C e D tem algo em comum.

São curvas fechadas. Elas não tem começo nem fim

Quando pensamos em curvas fechadas, logo associamos com a borda do copo, da xícara e ao chapeuzinho das festas infantis.

Essas curvas são círculos.

Mas, atenção! Nem toda curva fechada é círculo!

Figura 1

Figura 1: Imagens de oito curvas, tanto abertas quanto fechadas e também compostas com linhas retas.

Você deve ter percebido que as curvas $C$ e $D$ embora fechadas são diferentes.

Por que?

$\mathrm{O}$ que as difere?
Exemplos a até g:

Texto alternativo: Exemplos de curvas abertas e fechadas Descrição: São mostrados exemplos de curvas de várias naturezas, onde duas são fechadas. A curva $\mathrm{C}$ é um círculo e a curva $\mathrm{D}$ é uma elipse.

Note que a curva $D$, elipse, tem a parte central estreitada.Ela não é bem regular como o círculo.Ou seja, os dois eixos que a divide em duas partes iguais são diferentes, um é maior que o outro.

Esses eixos da elipse, no círculo ou circunferência são chamados de diâmetros e todos tem o mesmo tamanho. O diâmetro é uma reta que divide a circunferência em duas partes iguais, passando pelo seu ponto central.

Qualquer diâmetro que seja traçado, em qualquer ponto da circunferência, vai dividi-la sempre em duas partes absolutamente iguais.

Mas, atente que o diâmetro tem que passar pelo ponto central, obrigatoriamente.

\section{Navegação}

\section{Ao clicar em curvas fechadas vai para próxima página que aborda as} Curvas Cônicas

\section{Sai do objeto de aprendizagem}

Figura 5 Storyboard: Curvas abertas e fechadas 
A decisão de trazer tais conteúdos para o AVA baseou-se nas respostas de descrição de triângulos e retângulos, encontradas nos questionários. Eles não representavam a real configuração dessas figuras geométricas consideradas das mais básicas.

Nesse sentido, são encontradas telas como as que aqui são inseridas, trazendo figuras e suas descrições.

Estes Objetos de Aprendizagem somente serão considerados acessíveis se atenderem as recomendações de órgãos internacionais que tratam da acessibilidade nos conteúdos da web, Macedo (2010).

No contexto do trabalho em desenvolvimento, tem-se como norteadores o WCAG, o WAI (World Wide Web Consortium, Web Accessibility Iniciative.1999), o W3C (Accessibility contributes to Universal Design - Design for All), e o IMS (IMS Guidelines for Developing Accessible Learning Appllications), indicando meios de tornar os ambientes utilizáveis por uma maior quantidade de indivíduos, com e sem deficiência (MACEDO, 2010). Continuando a autora afirma que deve-se perseguir os princípios do "Design Universal, definido pela ONU como: concepção de espaços, artefatos e produtos que visam atender simultaneamente pessoas com diferentes características" constituindo-se nos elementos ou soluções que compõe a acessibilidade Macedo (2010).

$\mathrm{Na}$ área educacional é uma abordagem que obedece primariamente os três princípios: 1 - Múltiplos meios de representação para permitir o acesso à informação e conhecimento; 2 - Múltiplos meios de ação e expressão para que o estudante possa demonstrar o seu conhecimento; e 3 - Múltiplos meios para aproximar os interesses dos alunos, ofertarem desafios apropriados e ampliar a motivação". (CAST, 2008 APUD EM MACEDO 2010, PG. 142.)

As telas aqui inseridas exemplificam o princípio de abordagem dos conteúdos da geometria plana no AVA inclusivo, no entanto muitas outras podem ser elaboradas com novos exemplos, enriquecendo e melhor ilustrando outras situações e figuras. 


\section{Exemplos da vida real para retas}

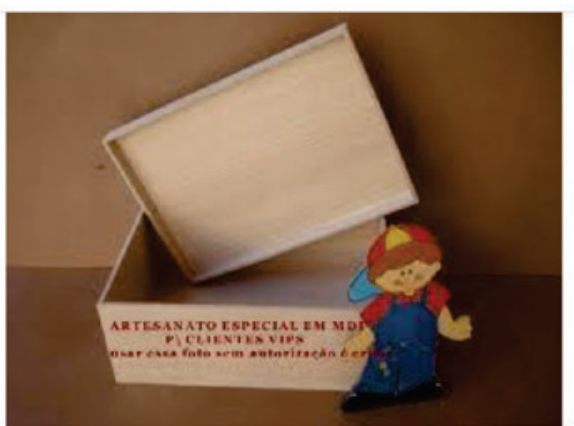

Figura 1

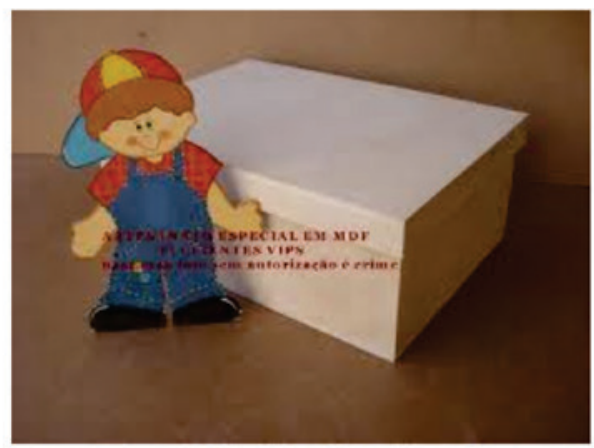

Figura 2

Na sua casa você vai encontrar uma caixa de sapatos. Vamos usa-la para nossos estudos. Pegue a caixa e tire a tampa.

Depois de destampada, quantos lados fechados ela tem? Identifique esses lados. Encontrou cinco?

Isso mesmo! São cinco.

Agora vamos aprender com a caixa. Cada lado se contra com o outro em uma linha e ela se chama aresta. Isso e uma reta, que é formada pela junção de dois lados e por isso é chamada aresta. Aproveite e vá gravando ai, que o nome desses lados da caixa é plano.

Logo, sua caixa aí tem 5 planos e 8 aresta, ou seja 8 retas. Se considerarmos que a tampa da caixa também é um plano, são 6 planos e 12 arestas, retas.

Agora vamos pensar: Se a caixa ficasse mesmo sem tampa, deixaria de existir as 4 retas do encontro da caixa com a tampa?

Que você acha?

Se você respondeu não, está mais que certo. As retas estariam lá assim mesmo.

Analise a caixa aberta. $\mathrm{Na}$ borda de cada lado (plano) tem uma reta que é o fim do lado. E a reta limite deste lado, a reta que limita a porção do plano.

E essa história de porção de plano? O que é? Você vai entender disso em breve. Vai precisar saber quando estudar as projeções!

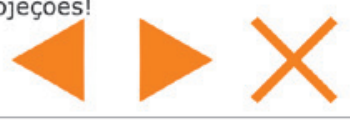

Figura 1: imagem de uma caixa de sapatos sem tampa com um bonequinho junto da caixa do lado direito.

Figura 2: imagem de uma caixa de sapatos tampada com um bonequinho junto da caixa do lado esquerdo.

Texto alternativo: Estudo das retas

Descrição: ilustraçao que mostra caixas de sapato aberta e fechada para auxiliar no estudo das retas, analogamente às arestas das caixas. Aproveita-se e já insere o conceito de plano, fazendo referência aos lados, faces das caixas de sapato.

\section{Navegação}

Fique ligado! Se você pode ver, observe as caixas das imagens e leia o texto com calma, observando a caixa.

Se você não vê, pegue sua caixa de sapatos e vá explorando com as mãos e ouvindo atentamente $o$ texto para entender bem. Você vai perceber que as retas estão em posições diferentes. Umas verticais e outras horizontais.

Isso fica fácil de entender se você apoiar sua caixa no chão.

As que ficam deitadas, paralelas ao chão são horizontais. As que ficam em pé, perpendiculares ao chão são verticais.

Na página anterior (voltar) você vai para o exemplo da xícara para ajudar a entender uma curva fechada. Na página seguinte continue estudando sobre retas. Depois de explorar bem esse conteúdo volte para a página 3.

\section{Sai do objeto de aprendizagem}

Figura 6 Storyboard: Uso de uma caixa para elucidar planos e posições de retas

Seguindo as diretrizes de Macedo (2010) com relação ao desenvolvimento de OA acessíveis, todos os textos e figuras serão audiodescritas podendo ser lidos por leitores de tela (que transmitem 
os textos às pessoas cegas) e haverá a possibilidade de transformar as imagens da tela em impressos com relevo e em Braille.

$O$ raio de abrangência do AVA-I estende-se desde estes primeiros estudos de formas básicas, que incluirão triângulos, quadriláteros e polígonos, além das figuras aqui exemplificadas, para retas e curvas, até o estudo da representação tridimensional.

\section{Figuras planas}

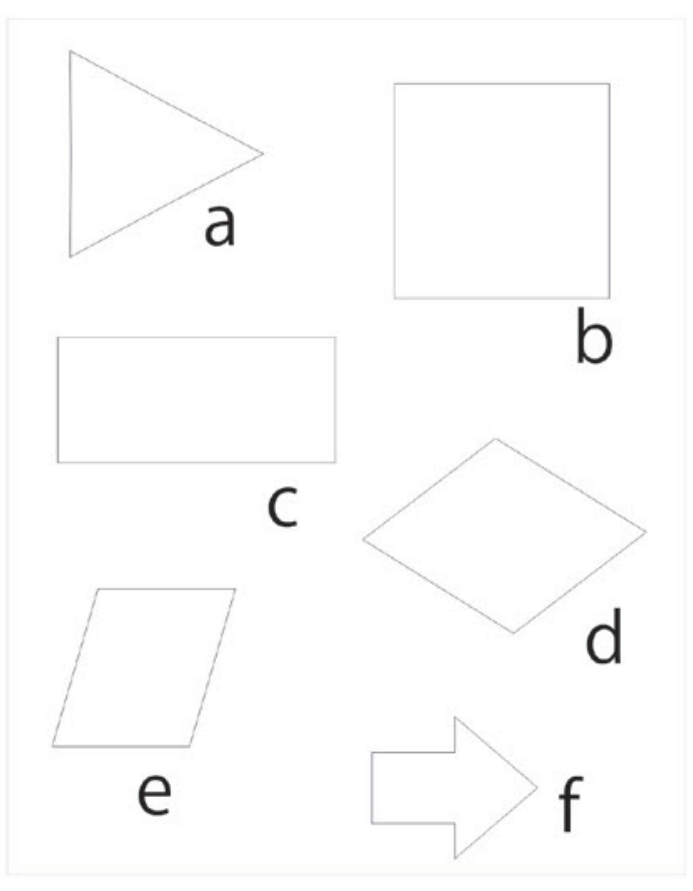

Figura 1
Agora vamos ver o que se pode fazer juntando várias retas.

Vamos formar figuras! E algumas delas são bem conhecidas e importantes.

NA Figura ao lado temos algumas delas, como triângulo, quadrado, retângulo, losango, paralelogramo e até uma seta formada pela junção de um quadrado e um triângulo.

Vamos estudar, entender e aprender essas formas básicas.

$\mathrm{O}$ triângulo ou trilátero, como o nome diz tem 3 lados que podem ser iguais ou diferentes entre si. Já o quadrado e o retângulo tem 4 lados, paralelos 2 a 2 . A diferença é que os 4 lados do quadrado são iguais. O losango também tem 4 lados, mas os ângulos que fazem entre eles não é de 90 graus como o quadrado e o retângulo.Já o paralelogramo tem seus lados opostos paralelos dois a dois, como o losango que é também um tipo de paralelogramo.

Você sabia que quase todos os ambientes de uma casa ou apartamento são quadrados ou retangulares? Então, se você pretende desenhar seu quarto, aprenda bem essas figuras.

E os móveis?

Geralmente tem contorno também quadrado ou retangular. Sua cama, por exemplo é retangular. Tem mesas redondas, ou circulares tanbém.

Qual a forma da mesa da sua casa?

Mas Atenção! Estamos falando do contorno desses objetos, sem levar em conta as alturas deles. Porque eles não são figuras planas. Quando consideramos seu volume entendemos que são sólidos tridimensionais.
Figura 1: imagem de várias figuras planas. São seis ao todo e mostram as figuras mais básicas.

Texto alternativo: Estudo de figuras planas

Descrição: ilustraçao que mostra seis figuras planas. A letra a mostra um triângulo, a letra b mostra um quadrado, a c um retângulo, a d um losango, a e um paralelogramo e a f uma seta larga formada pela junção de um quadrado com um triângulo. \}mprima a figura ao lado em impressora de relevo. Se você não tem uma, imprima em tinta e peça ajuda de alguém vidente para colocar relevo em cada figura. Avise que o relevo deve ser perfeitamente fiel à figura, logo, nos cantos onde uma reta encontra a outra, não deve ter nada curvado. Elas se encontram em ângulos, retos ou não retos, conforme cada caso.

Isso é uma observação importante para você, que deve treinar isso a fim de identificar as figuras com facilidade ao toca-las.

Procure relaciona-las com objetos do seu dia-a-dia. Por exemplo: seu caderno tem forma retangular.

\section{Navegação}

Na página anterior (voltar) você vai para o estudo das curvas cônicas. Na próxima tem os triângulos..

\section{Sai do objeto de aprendizagem}

Figura 7 Storyboard: Usando retas para formar figuras 
Nas etapas que abordarão esses estudos deverá ser dada atenção especial ao material desenvolvido para pessoas cegas, visto que trata de assunto complexo. Até mesmo para pessoas videntes, há grandes dificuldades quando precisam representar sob o plano bidimensional objetos com três dimensões.

A utilização do Sistema Mongeano, que relaciona as diversas projeções de um objeto nos planos em que são projetadas suas diversas faces, pode não ser viável nessa situação, apresentando-se como alternativa simplificadora o Sistema Cotado de representação gráfica. Neste sistema usa-se apenas uma projeção, acompanhada da sua cota, ou seja, da distância que separa seus pontos do plano de projeção. As pesquisas nessa direção ainda encontram-se em fase inicial.

\section{Considerações finais}

Prover um ambiente virtual acessível para ensino da geometria gráfica não se constitui tarefa fácil, notadamente quando o estudante é uma pessoa com cegueira.

Como colocado no texto, há a expectativa de poder desenhar, expressar algumas situações por parte dos usuários cegos.

Entretanto, no caso da elaboração de desenhos esquemáticos de plantas de ambientes por pessoas cegas, deve-se estabelecer uma linguagem mais simples para esses desenhos. Por exemplo: As convenções de desenho de paredes, janelas, portas e armários em planta, exigem linhas duplas, triplas ou quádruplas dependendo do que se quer representar. Tal configuração pode ser demasiado complexa para pessoas que não veem. Assim sugere-se o estabelecimento de novas convenções mais simples, mas que ao mesmo tempo, sejam de fácil identificação também por pessoas videntes.

Um dos resultados esperado a partir da utilização do AVA-I é permitir que a pessoa cega possa desenhar rotas, conseguindo explicitar o caminho a seguir até um determinado lugar.

A equipe multidisciplinar que vem trabalhando no projeto atua em diversas direções e em níveis diferenciados, na perspectiva de promover a todos os usuários o estudo independente e autônomo da matéria alvo do projeto.

Ao final da pesquisa o ambiente terá sido testado por pessoas que ao longo do processo foram entrevistadas e questionadas, colocando-se disponíveis para esta parceria.

A consecução dessa pesquisa trará contribuições significativas à área do Design da Informação, uma vez que aborda a acessibilidade na WEB, provendo um ambiente onde tais critérios são adotados e estimulados. A diversidade de informações encontradas na WEB muitas vezes não são acessíveis a pessoas com deficiência, dificultando o acesso a essa tecnologia a uma parcela da população que esteve excluída por muito tempo.

O design da informação baseado nos princípios do design universal provê acesso livre e ilimitado a todas as pessoas, com ou 
sem deficiência, a todo conteúdo desenvolvido por meio do projeto inclusivo permitindo a todos o direito à informação.

\section{Referências}

abbagnano, N. (2007). Dicionário de Filosofia. São Paulo: WMF Martins Fontes. ALmeIDA, M. F. X. M. (2008). Auxílios à navegação de pedestres cegos através de mapa tátil. Dissertação. Programa de Pós-graduação em Design. UFPE. Recife. Bourdieu, P. (1990). Coisas Ditas. São Paulo: Brasiliense.

CASTELlAR, SONIA. (2006). Educação geográfica: teorias e práticas docentes. São Paulo: Contexto. 167p.

FAÉ, M. (2011). Conteúdo para os alunos cegos, 2009. Disponível em http://www. agb.org.br/XENPEG/artigos/GT/GT3/tc3\%20\%2849\%29.pdf, Acesso em: 31 de julho 2011.

MACEDO, C. M. S. (2010). Diretrizes para criação de objetos de aprendizagem acessíveis. 2010. 271f. Tese (Doutorado em Engenharia e Gestão do Conhecimento) - UFSC, Florianópolis.

mazzotTa, M. J. s. (1996). Educação Especial no Brasil: História e políticas públicas. São Paulo: Cortez, 1996.

NCSU - CAST (2010). Universal Design. North Caroline State University - Center for Universal Design, 2008. Disponivel em: <http://www.ncsu.edu/www/ncsu/ design/sod5/cud/>. Acesso em: 11 outubro 2010.

NUNES, S. S.; LOMÔNACO, J. F. B. (2008). Desenvolvimento de conceitos em cegos congênitos: caminhos de aquisição do conhecimento. In Revista Semestral da Associação Brasileira de Psicologia Escolar e Educacional (ABRAPEE) Vol. 12 № 1. Janeiro/Junho. p 119-138

Stainback, S. W. (1999). Inclusão: um guia para educadores. Porto Alegre: Artes Médicas SuL.

\section{Sobre as autoras}

\section{Vilma Villarouco}

$<$ villarouco@hotmail.com>

Doutora em Engenharia de Produção/UFSC, Professora associada da UFPE. Docente do PPG em Design e em Ergonomia da UFPE.

\section{Angela R. B. Flores}

<arqangelaflores@gmail.com>

Mestre em PPG Arquitetura/UFSC. Doutoranda no PPG EGC/UFSC. Tem experiência na área de Arquitetura e Design de Interiores. Atua nos temas: idoso, moradia, qualidade de vida, AVA, acessibilidade e inclusão.

Artigo recebido em 8 out. 2013, aprovado em 12 dez. 2013. 